\title{
SER PROFESSORA: UM ESTILO DE VIDA PONTUADO PELA FORMAÇÃO
}

\author{
Rosimar Serena Esquisani \\ UPF \\ Flávia Obino Corrêa Werle \\ UNISINOS
}

\section{RESUMO:}

O trabalho discute o habitus como conceito apto a explicar o estilo de vida que assinala o 'ser professora'. Para tanto, lança mão de registros orais elaborados a partir de entrevistas com egressas da Escola Complementar. Por meio da identidade tecida na formação inicial destas ex-complementaristas, as mesmas internalizaram comportamentos próprios a um estilo de vida que supunham adequado ao exercício profissional, condicionando seus modos e hábitos pessoais à docência. Nesta direção, o texto procura agregar contribuições para o entendimento desse estilo de vida, no momento em que reafirma o conceito de habitus, como capaz de responder à especificidade da formação da identidade grupal dos sujeitos.

Palavras-chave: Habitus. Estilo de vida. Professora. Formação inicial.

\section{BE TEACHER: A LIFESTYLE FOR MARKED TRAINING}

\begin{abstract}
:
The work argues habitus as apt concept to explain the life style that designates 'to be teacher'. For in such a way, it launches hand of elaborated verbal registers from interviews with comingsof the Complementary School. Through the identity weaveeed in the initial formation of these formerones, the same ones they had assumed proper behaviors to a life style that assumed adequate to the professional exercise, conditioning its personal ways and habits the to be teacher. In this direction, the text looks for to add contributions for the agreement of this style of life, at the moment where it reaffirms the concept of habitus, as capable to answer to the specific one of the formation of the group identity of the citizens. Keywords: Habitus. Life style. Teacher. Initial formation.
\end{abstract}

Animadas pela ideia recorrente de que existe um jeito de ser professora e pelo possível reconhecimento e materialidade de um estilo de vida nutrido pela docência, procuramos sedimentar nossos argumentos em duas bases: uma teórica, sustentada em Pierre Bourdieu (de sobremaneira) e outra empírica, referendada em pesquisas com fontes orais.

Deste modo, subsidiado em grande medida, pelos estudos de Pierre-Félix Bourdieu (01/08/1930 - 23/01/2002), o texto expõe elementos para a compreensão do conceito de habitus empregado como mecanismo de formação docente que, de tão intenso, foi capaz de moldar um estilo de vida que assinala o 'ser professora'. Tal estilo de vida, forjado pelo processo de formação de ex-complementaristas, se mantém residual nas memórias de mulheres, professoras primárias formadas pela Escola Complementar. 
Para tanto, lança mão de registros orais elaborados a partir de entrevistas com egressas da Escola Complementar. Por meio da identidade tecida na formação inicial destas ex-complementaristas, as mesmas internalizaram comportamentos próprios a um estilo de vida que supunham adequado ao exercício profissional, condicionando seus modos e hábitos pessoais à docência.

As atitudes compatíveis com aquilo que se presumia ser a ordem social foram condicionadas, no imaginário destas mulheres, como sinônimo de realização pessoal e, sobretudo, profissional, definindo a forma como as mesmas encarariam, por toda sua trajetória, a si mesmas e a função de professoras, moldando um estilo de vida endereçado à profissionalização e nutrido por ela.

Nem mesmo a memória (pessoal, subjetiva) foge a regra do que é compatível com a ordem social, sendo que cristaliza-se uma memória coletiva, convergente nos pontos principais entre todos os que se sentem pertencentes aquele grupo. Definida como um "[...]conjunto de representações relativas ao passado que cada grupo produz, institucionaliza, cuida e transmite por meio da interação de seus membros" (JEDLOWSKI, 2005, p. 87), esta memória configura intensamente a identidade de ex-complementarista, sendo incorporada como intrínseca e 'natural' ao sujeito que narra.

\section{Caracterizando a pesquisa}

Qualquer pessoa que tenha passado pelo processo formal de escolarização conhece professores e deles tem referências. O senso comum costuma, inclusive, construir histórias, anedotas, jargões sobre o jeito de ser professor. E de onde vem este estilo de vida? Já nascemos com pré-disposição para incorporarmos, oportunamente, o jeito de ser professor? Óbvio que não! O que existe é um moldar-se a determinadas condições e entendê-las como parte do que se espera de um professor (postura, vestimenta, adereços, jeito de falar, gestual, frases prontas/clichês, opiniões e pontos de vista sobre assuntos ligados a educação, entre outros).

Em que local aprendemos este estilo de vida de professor? Na verdade, não há um espaço/tempo no qual se aprenda o jeito de ser professor, o estilo de vida que podemos caracterizar como típico de quem assume a profissão do magistério. O certo é que de algum lugar recolhemos as informações que irão compor aquilo que imaginamos, os outros esperam de um professor. Nossa hipótese é que este lugar seja a formação inicial.

Para auxiliar a compor este quadro, tomamos como referência o processo de formação inicial ocorrido em Escola Complementar, na primeira metade do século passado.

Grosso modo, situamos a Escola Complementar na alvorada do século XX, pois que:

[...] em 1906, foram criadas, no Rio Grande do Sul, Escolas Complementares em substituição aos Colégios Distritais, atendendo a alunos que se mostravam habilitados nas matérias do curso elementar, com o objetivo de desenvolver e aprofundar o ensino desse nível e de preparar candidatos ao magistério público primário, mediante estratégias de caráter privativo e profissional. Era um tipo de escola graduada, pois poderia ter vários professores segundo as seções em que o curso fosse dividido. O Curso Complementar não estava vinculado às estruturas de poder que intervinham politicamente na instrução pública da região, no que se diferençava da antiga Escola Normal. Embora formasse para o 
magistério público primário, não levava o nome de Escola Normal, tendo sido predominantemente desenvolvido, no Rio Grande do Sul, em instituições mantidas pela iniciativa privada. (WERLE, 2005, p. 620).

Sendo assim, a base empírica que fornece argumentos para as aproximações teóricas aqui encetadas, constitui-se por depoimentos orais de senhoras, excomplementaristas do Colégio São José, de São Leopoldo, sendo que tais depoimentos ${ }^{1}$ servem como campo de análise para o entendimento de como estas mulheres, formadas e formadoras, carregaram consigo a marca da sujeição a ordem social e o sentimento de pertencimento ao grupo, normatizador de ideias, vontades, sentimentos e estilos de vida.

O agir de acordo com a ordem social, "[...] que se confunde com a ordem do mundo" (Bourdieu, 1979, p. 48), passou para o imaginário destas senhoras como sinônimo de realização pessoal e sobretudo profissional, ditando o estilo como as mesmas organizariam suas vidas e encarariam, por todo o seu percurso, a si mesmas e a função da docência. Desta forma, o texto discute eventos de formação, ou episódios memorizados a partir do processo de formação inicial dos referidos sujeitos-narradores como professoras primárias, característicos do estilo de vida.

O acesso a tais eventos se dá pelo trabalho com a memória dos sujeitos-narradores, a partir da pesquisa com fontes orais, considerando que "[...] a memória é, por excelência, o trabalho que organiza, busca, junta, rejunta, cola, desmonta, dando uma configuração às imagens que desenham novas subjetividades" (OLIVEIRA, 2004, p. 16).

Da mesma maneira que acessar o modo como "[...] cada pessoa se forma, como a sua subjetividade é produzida, permite-nos conhecer a singularidade da sua história, o modo singular como age, reage e interage com os seus contextos" (OLIVEIRA, 2004, p.17), acessar as memórias dos processos formativos permite associar tais processos a conceitos permanentes, como a cosmovisão, tendo em vista tratar-se do sujeito histórico que está posto em questão no processo de formação.

Além do que é o sujeito narrador que separa, escolhe, ordena, condiciona consciente ou inconscientemente o que será informado, pois "[...] o passado nunca permanece uno e idêntico a si, mas é constantemente selecionado, filtrado e reestruturado por questões e necessidades do presente, tanto no nível individual como no social" (JEDLOWSKI, 2005, p. 87).

Isto significa que pesquisar sobre professores e suas trajetórias é, em qualquer tempo, trabalhar com um contexto muito anterior a prática em si, ao dia a dia, a vida funcional. É levar em conta o período de formação, de "formar para ação", e o período ainda anterior a este, a história de vida de cada um dos sujeitos, o que os trouxe, em última instância, a preparação para e ao exercício do magistério.

Neste sentido, a formação destes sujeitos-narradores é determinante para jogar uma luz sobre o estilo de vida dos mesmos, assumido como natural e inerente a sua condição de professora "pela vida afora", considerando os condicionantes da instituição, como símbolos, ritos e grupalidade.

Isto leva a indagações sobre a marca que uma instituição é capaz de produzir em um sujeito a ela vinculado, configurando trajetórias e moldando visões de mundo com tamanha intensidade que é impossível separar, mesmo nas memórias (subjetivas), o sujeito que narra da instituição narrada, no qual as perguntas que precedem a reconstituição da memória são da seguinte monta: "[...] que lembranças têm os professores do cotidiano das escolas que fizeram parte de sua formação? Que práticas e que modelos the acionaram

$1 \quad$ As entrevistas foram realizadas no contexto do projeto de pesquisa "Escola Complementar: Práticas e Instituições" - 2001/2003, com apoio da Fapergs e CNPq. 
dispositivos de produção do ser professor? Que professores e que performances são lembradas através do trabalho da memória?" (OLIVEIRA, 2004, p.14). Tais indagações residem para além da formalidade institucional, ou seja, vão além de uma menção em um diploma de conclusão de curso. Tais indagações vinculam-se ao habitus formado e formador, a marca indelével impingida à conformidade dos sujeitos-narradores.

\section{O habitus e o estilo de vida}

O trabalho com a memória remete à interpretação, o que lança os depoimentos à condição de história, visto ques "[...] desde que haja rastro, distância, mediação, não estamos mais dentro da verdadeira memória, mas dentro da história" (NORA, 1993, p. 09). De outra forma, a memória serve de apoio para que conformações sejam desnudadas, não mais na exposição do sujeito, mas na decodificação das identidades coletivas estruturadas por meio das heranças plasmadas, que permitem sua passagem à condição de história.

Torna-se forçoso ainda, reconhecer a centralidade da instituição escolar na formação do habitus. Tal centralidade extrapola os currículos oficiais, pois:

[...] os espaços educativos, como lugares que abrigam a liturgia acadêmica, estão dotados de significados e transmitem uma importante quantidade de estímulos, conteúdos e valores do chamado currículo oculto, ao mesmo tempo em que impõem suas leis como organizações disciplinares (ESCOLANO, 1998, p. 27).

Nesta perspectiva, as instituições escolares guardam símbolos, ritos e valores que presentificam-se no sujeito a elas condicionado de forma mais inexorável do que os conteúdos ensinados no espaço da sala de aula, ou, como remete um dos sujeitosnarradores: "Então, tu vais sentir [referindo-se a entrevistadora], através daquilo que eu guardei [memória], alguma coisa que vai te explicar; o que havia naquela escola que era tão importante" (Entrevista 06).

Este olhar perspectivado sobre a instituição escolar permite auxiliar no ato de desvendar esta marca institucional expressa nos sujeitos. Para tal tarefa, o pensamento de Pierre Bourdieu empresta conceitos/ferramentas, no qual vincula como imperativo fundamental da chamada ética da conformidade, o respeito aos ritmos temporais, assim descrita:

[...] conformar-se com a ordem social é primordialmente respeitar os ritmos, acompanhar a medida, não andar fora do tempo. Pertencer ao grupo, significa ter o mesmo momento do dia e do ano, o mesmo comportamento de todos os outros membros do grupo (BOURDIEU, 1979, p. 47-48).

Os ritmos cadenciados e a vinculação compulsória a eles refletem o pertencimento ao grupo, naturalizando sentimentos e forjando um estilo de vida adequado àquele grupo, identificado pela própria lógica do convívio.

De acordo com Lahire (2002, p.150), “[...] o mundo social é feito de confrontações permanentes com situações não escolhidas, que se impõem aos atores e nas quais é preciso improvisar ao máximo". Nesta direção o sujeito improvisa sim, mas apenas dentro de uma dada ordem de mundo já pré-existente, sendo que segue modelos pré-estabelecidos do que 
se espera de alguém como ele, pertencente aquele grupo, em um determinado momento conjuntural.

Desta forma, "[...] a ordem social é antes de mais nada, um ritmo, um tempo" (BOURDIEU, 1979, p. 47). O disciplinamento aparece como poderoso ordenador dos ritos e ritmos (e, portanto, dos tempos), indicando os papéis a serem desempenhados e os locais adequados para tanto, estabelecendo-se como o dispositivo que estabelece e corporifica o vínculo de pertencimento.

O conceito de dispositivo apresenta-se no pensamento foucaultiano como

[...] um conjunto decididamente heterogêneo que engloba discursos, instituições, organizações arquitetônicas, decisões regulamentares, leis, medidas administrativas, enunciados científicos, proposições filosóficas, morais, filantrópicas. Em suma, o dito e o não dito são elementos do dispositivo. O dispositivo é a rede que se pode tecer entre estes elementos (FOUCAULT, 2000. p. 244).

O controle e a disciplina fazem parte do quadro moldural no qual a ordem social se funda e é integramente seguida por todos os sujeitos que desejam pertencer a esta ordem social, uma vez que não há reconhecimento grupal fora deste quadro.

Não se podia conversar na fila, no estudo, no refeitório somente depois que a irmã se mexia é que a gente podia falar. Era muito rígido, a irmã $[\ldots]$ era de uma firmeza impressionante [...] tinha fila de uma sala para outra e ninguém podia falar" (Entrevista 02 ).

Havia a irmã [...], que era uma mulher morena uma freira de um valor. Ela era prepotente, porque ela dominava um auditório, entendeu. Havia quatrocentas alunas no auditório na maior algazarra, uma ficava na porta controlando, quando a Irmã [...] se aproximava ela fazia assim [gesticula] na porta. Era o que bastava prá todo mundo entrar e se acomodar, né? (Entrevista 03).

Assim, a instituição plasma-se ao indivíduo, configurando cada sentimento e sentido, seja pelos ritos e ordens disciplinares, seja pela permanência integral dentro da instituição.

Elas faziam um pouco de diferença entre as internas e as externas. As internas tinham a noite, os dormitórios. Tanto é que, se tu falares com a $[\ldots]$ e com a [...] que foram internas, elas tem uma visão muito mais arraigada da escola: ali era a casa delas, elas passavam a vida ali dentro [...] Já nós (externas) terminávamos a as aulas as 5 horas e íamos para outra, tínhamos aniversários das coleguinhas. Elas (internas) tinham uma vez por mês ida para casa. Aos sábados, passeavam em São Leopoldo, duas a duas, com a Irmã do lado. A única coisa que elas tinham era o passeio. Quando havia o cartão Não Satisfatório, perdiam o passeio, perdiam a saída, só no outro mês [...] (Entrevista 04).

E o agir de acordo com a disciplina imposta e a ordem social, estabelecendo um estilo de vida compatível com o que imaginavam ser digno do exercício da docência, passou para o imaginário destas senhoras como sinônimo de realização pessoal e coletiva. A memória, ao contrário de uma possível insurreição contra a rotina disciplinada, atribui a esta cadência a condição de sucesso, regada pelo sentimento de pertencer, de estar incluído em um grupo naturalmente "vencedor". 
Outra narradora, ex-complementarista do São José, revela que:

[...] sabe, tem turmas que marcam, e o Colégio São José de São Leopoldo, foi tudo na minha vida, por isso eu não..., todos os outros cursos que eu fiz de extensão universitária, curso de psicologia que eu fiz uns dezoito aqui em Montenegro, vão ser de caráter universitário de terceiro grau nada disso conta, pra mim só conta o Curso Complementar, que eu fiz, me formei e dele é que eu vivi a vida inteira (Entrevista 06).

O fato de "só"/apenas contar para a entrevistada o Curso Complementar em destaque, mas ter estudado no Colégio São José de modo geral, está diretamente ligado à maneira como esta senhora vê tanto a um quanto ao outro, como sinônimos de uma dada ordem social a qual ela se enxerga como pertencente ou quer pertencer, mesmo depois de tanto tempo passado,

Ele [Colégio São José] me deu o direito de ser, em qualquer escola onde eu estava, um destaque, sempre fui destaque, por causa do curso que eu recebi. O Curso Complementar, era dirigido pela Irmã [...], uma alemã, cor nobre e a diretora da escola era a Irmã [...]. Essas duas personalidades juntas, elas formaram, assim, acho que dezenas, dezenas de professoras, que por todo esse Rio Grande do Sul, é do Colégio São José de São Leopoldo, já se sabia que era uma professora ou uma diretora de alto valor pedagógico, entendeu, e líder. Interessante, que elas passavam uma liderança prá gente. (...) Nós tivemos uma educação, nesses três anos, castelã, porque ela vinha de um castelo, então ela passou pro Colégio São José de São Leopoldo uma educação castelã, nos éramos assim diferentes, [...] no São José de São Leopoldo era outra maneira de ser (Entrevista 06).

Cristalizou-se, nas entrevistadas, a ideia de que tendo estudado no São José elas haviam sido "preparadas mesmo" (Entrevista 08) para o exercício do magistério em qualquer instância, para ocupar qualquer cargo, diante de qualquer situação.

Eu aceitei de tu vires falar, aqui [referindo-se a entrevistadora] por uma questão muito simples, porque em primeiro lugar, se eu não tivesse feito esse curso, eu não teria sido o que sou [...] ele me deu o direito de ser, em qualquer escola onde eu estava, um destaque, sempre fui destaque por causa do curso que eu recebi, o Curso Complementar (Entrevista 06).

Tratava-se de algo além de um diploma. Tratava-se de um estilo de vida, de uma conduta presumível, de um modo de ser.

Eu devo tudo a este colégio, o que sou, o que eu fui, os meus destaques em cultura, em todas as obras, eu nunca precisei mais estudar português [...] A formação era integral, ela abrangia o indivíduo, abrangia a parte física, a parte intelectual,a parte moral e nos dava assim, eu não sei o que é! (Entrevista 06).

Nossa colaboradora não conseguia traduzir em palavras, expressar o que o Colégio lhe dava exatamente, por estar convencida de que ter estudado naquela instituição lhe afiançava poderes para aferir um estilo de vida especial, diferenciado, único e característico que quem tinha a docência por compromisso e modelo social de conduta. 
Eu quero que cite, porque ao Colégio São José eu devo tudo o que eu sou, entendeu. Em didática eu nunca perdi, para nenhuma formada em faculdade, com mestrado com doutorado, em didática (Entrevista 02).

Eu sempre digo que o São José foi uma escola sob todos os aspectos nas nossas vidas. Formação religiosa, formação pedagógica, formação cultural, formação social (Entrevista 01).

Do mesmo modo, a ordem e a disciplina assumidas pela escola, configuravam uma importante característica do projeto de formação de professoras, sendo que resiste na memória a ideia de que comportar-se de acordo com a disciplina imposta não tratava-se de submissão, mas de estilo de vida compromissado.

Eu passei 6 anos interna no colégio São José. E eu acho que esses métodos todos que a gente tem, de ordem, de disciplina, vem todos de lá. Porque nós saímos de casa, éramos meninas, pra ser internadas. Então, quem nos moldou foram elas, né? (Entrevista 01).

Além do mais, ter passado pelo São José era motivo encontrar-se apropriada/digna de fazer parte de uma determinada condição, senão social/financeira, ao menos simbólica:

[...] civilidade aos sábados à tarde das duas até às três e meia [...] Só para as internas. Como sentar, com assoar o nariz, como ir ao banheiro, como se portar, como caminhar, como vestir, como cruzar as pernas, não se podia, se quer cruzar as pernas, caminhar, como caminhar, como andar... [...] Então aquela civilidade te dava poderes de tu enfrentar qualquer ambiente social [...] (Entrevista 06).

O próprio estilo de vida dos professores formadores conformava o pertencimento ao grupo e a certeza de que aqueles modelos de vida deveriam ser os corretos e, portanto, seguidos.

Professores, eu acho, que são a base para formar um aluno, se não tem professor, termina o aluno, porque professor que não sabe, não pode ensinar, mas a nossa formação, não digo perfeita, porque não há nada perfeito no mundo, mas nós tínhamos tudo (Entrevista 06).

Agora, nós tivemos, nós tivemos sorte de ter muito bons professores, né? Todos eles eram bons professores, tanto as irmãs como os professores leigos, eram bons professores. Agora sempre muito exigentes conosco, né? Elas exigiam o máximo (Entrevista 02).

Os professores leigos, no contexto de uma escola confessional, representavam o arquétipo de conduta e estilo, pois tais sujeitos

[...] agiriam orientados por uma estrutura incorporada, um habitus, que refletiria as características da realidade social na qual eles foram anteriormente socializados. Instala, assim, uma importância à dimensão do aprendizado passado e afirma que este está no princípio do encadeamento das ações, portanto a prática é resultado de um habitus incorporado a partir de uma trajetória social (NOGUEIRA; NOGUEIRA, 2004, p. 33). 
Da mesma maneira, a condição social das egressas da escola condiciona, na memória de uma das entrevistadas, o status de pertença a uma classe social, graças ao vínculo de pertencimento a mesma instituição escolar:

[...] era um colégio de tanta fama que vinham moças estudar aqui de todo o Brasil, inclusive as filhas do presidente Getúlio Vargas estudaram aqui [...] Tinha toda essa gente rica, fazendeiros naquela época, havia muitos, né. [...] Era tudo gente importante, que essas moças ai todas a maioria eram internas, todas filhas de gente rica: fazendeiros, estancieiros. Vinha tudo para cá. Era um colégio de muita fama. (Entrevista 05).

A força simbólica da estada nestas instituições acompanhava seus egressos para além dos seus portões, definindo rumos pessoais e profissionais. Desta sorte, como construção histórica, o habitus não está desindexado de sua produção humana, sendo que a submissão a ordem não se dá sem a consciência da mesma:

Princípio de uma autonomia real em relação às determinações imediatas da "situação", o habitus não é por isto uma espécie de essência ahistórica, cuja existência seria o seu desenvolvimento, enfim destino definido uma vez por todas. Os ajustamentos que são incessantemente impostos pelas necessidades de adaptação às situações novas e imprevistas podem determinar transformações duráveis do habitus, mas dentro de certos limites: entre outras razões porque o habitus define a percepção da situação que o determina. (BOURDIEU, 1983, p. 106).

Isto levou a um certo estilo de vida, no qual moldaram-se professoras apegadas a uma determinada ordem de mundo e ao status do qual dispunham em seus momentos de formação, pode ser percebido neste outro depoimento, que relata o evento causado pelo "São José na rua", pois “[...] naquele tempo tinha muita fama as gurias do São José, meu Deus, quando saía o colégio assim para passear, há, saíam assim em fileira para dar uma volta em São Leopoldo. Enchia todo mundo para ver o São José passar" (Entrevista 02).

Sobre este assunto, Bourdieu chama atenção para

[...] a correspondência que se observa entre os espaços das posições sociais e o espaço dos estilos de vida resulta do fato de que condições semelhantes produzem habitus substituíveis que engendram, por sua vez, segundo a sua lógica específica, práticas infinitamente diversas e imprevisíveis em seu detalhe singular, mas sempre encerradas nos limites inerentes as condições objetivas das quais elas são produto e às quais elas estão objetivamente adaptadas [...] O estilo de vida é um conjunto unitário de preferências distintivas que exprimem, na lógica especifica de cada um dos subespaços simbólicos, mobília, vestimentas, linguagem ou hexis corporal, a mesma intenção ex-pressiva, principia da unidade de estilo que se entrega diretamente à intuição e que a análise destrói ao recortá-lo em universos separados (BOURDIEU, 1996, p. 82-83)

O que leva, ainda dentro da teoria do sociólogo francês, a formação do capital social, outro conceito que pode ser aglutinado a um estudo sobre ritmos de grupos como referenciais da ética da conformidade.

Bourdieu chama de capital social ao 
[...] conjunto de recursos atuais ou potenciais que estão ligados à posse de uma rede durável de relações mais ou menos institucionalizadas de interconhecimento e de inter-reconhecimento ou, em outros termos, à vinculação a um grupo, como conjunto de agentes que não somente são dotados de propriedades comuns (passíveis de serem percebidas pelo observador, pelos outros ou por eles mesmos), mas também são unidos por ligações permanentes e úteis (BOURDIEU, 1998 p. 67).

Tanto a conformidade quanto a transgressão, que pautam-se no tempo como motor e ditador de ritmos, acontecem em um espaço, ao qual Bourdieu nomeou de espaço social. O conceito de espaço social para esse autor, é quase um oxímoro, da mesma forma que corrobora, nega as homogeneidade do grupo, a partir do princípio que a noção de espaço permite pensar a realidade enquanto conjunto de relações:

Os seres aparentes, diretamente visíveis, quer se trate de indivíduos quer de grupos, existem e subsistem na e pela diferença, isto é, enquanto ocupam posições relativas em que um espaço de relações que, ainda que invisível e sempre difícil de expressar empíricamente, é a realidade mais real (ens realissimum como dizia a escolástica) e o princípio real dos comportamentos dos indivíduos e dos grupos (BOURDIEU, 1996, p. 48).

Neste ponto servimo-nos do conceito de habitus, ou o

[...] sistema de disposições duráveis, estruturas estruturadas predispostas a funcionar como estruturas estruturantes, isto é, como princípio gerador e estruturador das práticas e das representações que podem ser objetivamente 'regulamentada' e 'reguladas' sem ser o produto de obediência a regras, objetivamente adaptadas a seu fim sem supor a intenção consciente dos fins e o domínio expresso das operações necessárias para atingi-los e coletivamente orquestradas, sem ser o produto da ação organizadora de um regente (BOURDIEU, 1994, p.61).

A partir desta perspectiva, as ações pautadas, "orquestradas" das senhoras excomplementaristas em seu tempo de formação inicial, no Colégio São José, diz muito da "prática" do conceito de habitus Bourdiano. Essas ações estavam alocadas dentro de padrões pré-estabelecidos e, portanto, aceitas pelo grupo social. Não são, assim, geradoras de conflitos entre ele e os outros membros do grupo. Desta forma, esse repertório não apenas assegura a adequação entre as ações do indivíduo e a realidade objetiva, mas, sobretudo, assegura, que essa adequação se realize com um mínimo de esforço e de conflitos. A este respeito Bourdieu é esclarecedor ao afirmar que:

As práticas que o habitus produz (enquanto princípio gerador de estratégias que permitem fazer face a situações imprevisíveis e sem cessar renovadas) são determinadas pela antecipação implícita de suas consequências, isto é, pelas condições passadas da produção de seu princípio de produção de modo que elas tendem a reproduzir as estruturas objetivas das quais elas são, em última análise, o produto. (BOURDIEU,1994, p. 61).

Tanto uma relação quanto a outra (hábitus ou ética da conformidade), Bourdieu exemplifica da seguinte maneira: 
O melhor exemplo de disposição é, sem dúvida, o sentido do jogo: o jogador, tendo interiorizado profundamente as regularidades de um jogo, faz o que faz no momento em que é preciso fazê-lo, sem ter a necessidade de colocar explicitamente como finalidade o que deve fazer (BOURDIEU, 1996, p.62).

Neste sentido, entre jocosa e trágica, está a fala de uma ex-complementarista lembrando que uma de suas ex-colegas não aguenta ouvir o barulho de sino, pois era sino para tudo, para estudar, para fazer as refeições, assear-se... "Tinha fila de uma sala para a outra e ninguém podia falar. Tinha um sino que tocava para cada aula. Até hoje, tem uma colega minha que não pode ouvir o sino. Ela tem vontade de pegar o sino e jogar longe. Era sino para aula, sino para missa, etc [...]" (Entrevista 08).

O sino, na verdade, simboliza / corporifica uma instituição na medida em que exerce o papel de instrumento condicionador do tempo e dos ritmos do grupo, marcando sonoramente a ritualidade da formação, elemento físico que auxiliava na manutenção da disciplina e das subordinações aos tempos coletivos da grupalidade e, é claro, calando fundo nas alunas.

[...] as situações sociais nas quais vivemos constituem verdadeiros 'ativadores' de resumos de experiências incorporados que são os nossos esquemas de ação ou nossos hábitos que dependemos assim fortemente desses contextos sociais que tiram de nós certas experiências e deixam outras em estado de gestação. Mudar de contexto é mudar as forças que agem sobre nós (LAHIRE, 2002, p. 59).

Se, contudo, o sujeito não mudar de contexto (como no caso em estudo), é lícito pensar que utilizará os mesmos hábitos ao longo da vida, certos de que estes, bem forjados em uma situação contextual dada, são os que se esperam dele em qualquer situação.

\section{Tecendo conclusões...}

As disposições duráveis elaboradas e cristalizadas nos sujeitos-narradores, condicionando-as a aceitarem e reproduzirem por meio da memória determinada ordem social e simbólica, como força de um grupo e de uma identidade aos quais ainda sentem-se vinculadas expressa, na medida, a força do habitus como dispositivo vinculado à formação de professores.

Trata-se de um estilo de vida que entendem próprio para quem carrega a marca da profissão docente, a sobrevivência de um jeito de ser, de um estilo de vida mediante a "[...] interiorização da exterioridade e de exteriorização da interioridade" (BOURDIEU, 1994, p.60). Nesta direção, a concepção de hábitus remete a um "[...] modus operandi, ou seja, como disposição [aprendida] para se operar numa determinada direção" (ORTIZ, 1994, p. 14).

E se o conceito de habitus leva ao entendimento de tempos e grupos dentro de uma certa ordem de mundo, nada mais competente em sua tarefa de instaurar uma dada visão ordenada de mundo do que a Escola Complementar, segundo os relatos colhidos, tanto que décadas depois permanece a identificação pessoal e profissional da ex-complementaristas.

Nesta direção, o texto procura agregar contribuições para o entendimento desse estilo de vida, no momento em que reafirma o conceito de habitus (Bourdieu), como capaz de responder a especificidade da formação da identidade grupal dos sujeitos. 
Em uma época que “[...] então para a mulher tinha que ser professora ou dona de casa" (Entrevista 04) a formação docente organizava não apenas o modo de ser professora, mas também o modo de ser mulher, fundamentando não apenas uma profissão, mas um estilo de vida.

A disciplina, a hierarquia e a rigidez esculpiram a sujeição a ordem social e simbólica de tal forma que é impossível insubordinar-se sem parecer indigno do título de professora. O título, o grau, a formação para a docência ligaram-se visceralmente à lógica de pertença e sujeição e tal lógica molda um estilo de vida próprio e encarado como natural a quem merece o título de docente.

Destarte, o texto assume a intenção de auxiliar na escrita de uma história (interpretada pelos olhos das pesquisadoras, é bem verdade), história de conformidade e formação, de pertencimento a instituição, onde esta faz-se tão forte que precedeu o indivíduo, relatos de uma história construída não na singularidade das naturezas individuais, mas no relacionamento proporcionado pelo convívio coletivo.

\section{REFERÊNCIAS}

BOURDIEU, Pierre. O Desencantamento do Mundo: estruturas econômicas e estruturas temporais. São. Ed. Perspectiva: São Paulo, 1979. 135p.

Questões de sociologia. Rio de Janeiro: Marco Zero, 1983.

Sobre o poder simbólico. In: BOURDIEU, Pierre. O poder simbólico. Lisboa: DIFEL, 1989. p. 7-15.

Esboço de uma teoria da prática. In Renato Ortiz (Org.), Pierre Bourdieu. São Paulo: Ática, 1994, p.46-81.

Razões Práticas - Sobre a teoria da ação. Campinas: Papirus, 1996.

$231 p$.

Escritos de educação. Petrópolis: Vozes, 1998. 251p.

ESCOLANO, Augustín. Arquitetura como programa. Espaço-escola e currículo. In: VIÑAO

FRAGO, Antônio; ESCOLANO, Augustín. Currículo, espaço e subjetividade. Rio de Janeiro: DP\&A, 1998. 151p.

FOUCAULT, Michel. Sobre a história da sexualidade. In: FOUCAULT, Michel. Microfísica do poder. Rio de Janeiro: Graal, 2000. 295p.

JEDLOWSKI, Paolo. Memória e a mídia: uma perspectiva sociológica. In: SÁ, C.P. (Org.) Imaginário e representações sociais. Rio de Janeiro: Museu da República, 2005. p. 8798.

LAHIRE, Bernard. Homem Plural. Os determinantes da ação. Trad. Jaime A. Clasen. Petrópolis, RJ: Vozes, 2002.

NORA, Pierre. 1993. Entre memória e história: a problemática dos lugares. Revista Projeto História. São Paulo, no. 10, p. 7-28. dez. 1993.

NOGUEIRA, Maria Alice; NOGUEIRA, Cláudio M. Martins. Bourdieu e a Educação. Belo Horizonte: Autêntica, 2004. 128p. 
OLIVEIRA, Valeska Fortes de. A formação de professores revisita os repertórios guardados na memória. In: OLIVEIRA, Valeska Fortes de (Org.). Imagens de professor significações do trabalho docente. 2. ed. Ijuí: UNIJUÍ, 2004. p.11-23.

ORTIZ, Renato. Introdução. In: ORTIZ, Renato (Org.). Pierre Bourdieu/ Sociologia. Trad. Paula Monteiro. 2.ed. São Paulo: Ática, 1994, p.14-25. (Coleção Grandes Cientistas Sociais).

WERLE, Flávia Obino Corrêa. Práticas de gestão e feminização do magistério. Cadernos de Pesquisa. São Paulo, v. 35, n. 126, p.609-634, set./dez. 2005.

Artigo recebido em: 03/05/2010

Aprovado em: 19/6/2010 